Article

\title{
Evaluation of the Textural Parameters of Zeolite Beta in LDPE Catalytic Degradation: Thermogravimetric Analysis Coupled with FTIR Operando Studies
}

\author{
Kamila Pyra $^{1, *}$, Karolina A. Tarach $^{1}{ }^{\mathbb{D}}$, Ewa Janiszewska ${ }^{2}{ }^{\mathbb{D}}$, Dorota Majda ${ }^{1}$ and

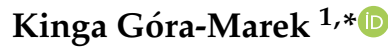 \\ 1 Faculty of Chemistry, Jagiellonian University, 30-387 Kraków, Poland; karolina.tarach@uj.edu.pl (K.A.T.); \\ majda@chemia.uj.edu.pl (D.M.) \\ 2 Faculty of Chemistry, Adam Mickiewicz University, 61-614 Poznan, Poland \\ * Correspondence: kamila.pyra@doctoral.uj.edu.pl (K.P.); kinga.gora-marek@uj.edu.pl (K.G.-M.); \\ Tel.: 00-48-12-686-2483 (K.P.); 00-48-12-686-2460 (K.G.-M.)
}

Academic Editor: Susana Valencia

Received: 22 January 2020; Accepted: 15 February 2020; Published: 19 February 2020

\begin{abstract}
Zeolite-based catalysts are globally employed in many industrial processes, such as crude-oil refining and bulk chemical production. In this work, the cracking of low-density polyethylene (LDPE) was thoroughly followed in a FTIR operando study to examine the catalytic efficiency of purely microporous zeolites $\beta$ of various textural characteristics. To provide complementary and valuable information on the catalytic activity of the zeolite $\beta$ studied, the thermogravimetric analysis results were compared with yields of the products generated under operating conditions. The reaction products were analyzed via GC-MS to determine the hydrocarbon chain distribution in terms of paraffin, olefins, and aromatics. The individual impact of textural and acidic parameters on catalytic parameters was assessed. The accumulation of bridging hydroxyls of high strength in the zeolite $\beta$ benefited the decrease in polymer decomposition temperature. Through a strategic comparison of purely microporous zeolites, we showed that the catalytic cracking of LDPE is dominated by the acidic feature inherent to the microporous environment.
\end{abstract}

Keywords: hierarchical zeolites; FTIR operando spectroscopy; polyethylene cracking

\section{Introduction}

The acidic characteristics of zeolite $\beta$ originate from its broad range of $\mathrm{Si} / \mathrm{Al}$ ratios and its particular structure disordered in one dimension, as a result of polymorph intergrowth [1-4]. The three-dimensional interconnected channel system built up from 12 rings classifies zeolite $\beta$ as a large-pore three-dimensional (3D) zeolite. Zeolite $\beta$ is widely reported as a solid acid catalyst, particularly addressed to cracking [5-7], (hydro)isomerization of alkanes [8,9], and alkylation of aromatics [10-12]. Aguado et al. [13] examined products gained from catalytic cracking of low- and high-density polyethylene (LDPE and HDPE) and polypropylene (PP) over zeolites $\beta$ synthesized via various methods, evidencing good selectivity toward $C_{5}-C_{12}$ hydrocarbons. Manos et al. [14] using zeolites H $\beta$, HZSM-5, and USY for the catalytic degradation of HDPE showed that the product distribution depends on the zeolite structure. In addition, they indicated the high selectivity of catalyst $\beta$ to the $C_{5}-C_{12}$ alkanes.

Understanding the structure-activity relationship of zeolitic catalysts in many reactions still remains an engaging research topic for the scientific community. The activity of acidic catalysts depends not only on the specific structural and topological properties but also on the nature of active sites. The concentration, accessibility, and acid strength of the Brønsted and Lewis sites are usually 
identified in the spectroscopic or thermogravimetric adsorption studies of basic probe molecules. The individual effects of textural and acidic features on the catalytic performance can be assessed only if the respective impacts are decoupled [15]. Therefore, the straightforward correlations between catalytic activity and properties of zeolites can be determined within the same zeolitic topology.

Through a strategic comparison of zeolites $\beta$ with tuned microporous characteristics, we showed that the catalytic cracking of LDPE over 12-ring zeolite $\beta$ is ruled by the acidic feature. Different synthesis methods were applied to obtain zeolites $\beta$ possessing tuned microporous features [16-18]. The zeolites were synthesized through the protozeolytic unit-based method. Then, the organosilane functionalization was done to modify the morphological and textural zeolite features and prevent crystal growth during further crystallization. To follow the influence of functionalization, the zeolite without this step was also synthesized. Finally, the acidic treatment over the functionalized sample was done to adjust the acidic properties. Commercially available zeolite served as the reference material. This work aims to show that the attenuation of the dispersive interactions between the fragments of LDPE chains and the $\mathrm{Si}(\mathrm{OH}) \mathrm{Al}$ in the confined voids of micropores significantly affects the catalytic behavior.

\section{Results}

\subsection{Physicochemical Properties of the Catalysts}

Well-resolved reflections representative of the BEA ${ }^{*}$ structure (Figure 1A) were found in the XRD patterns of the commercial zeolite $\beta$ and zeolites obtained from the protozeolytic unit-based synthesis method $\left(\beta_{0}, \beta_{\mathrm{G}}\right)$. All the zeolites exhibited both type I and type IV $\mathrm{N}_{2}$-isotherms corresponding to the porosity originating from the highly developed microporous characteristics $\left(\mathrm{V}_{\text {micro }}\right.$ and $\mathrm{S}_{\text {micro, }}$, Table 1 , Figure 1B). The high-pressure hysteresis loop pointed to the presence of interparticle porosity [19]. The mild treatment of $\beta_{\mathrm{G}}$ with $\mathrm{HNO}_{3}$ solution slightly improved the microporous parameters $\left(\mathrm{V}_{\text {micro }}\right.$ and $\mathrm{S}_{\text {micro }}$ ), while the value of $\mathrm{Si} / \mathrm{Al}$ ratio was kept within the range of 19-22 for all the zeolites studied. The studied zeolites were purely microporous materials, and neither functionalization with organosilane nor acid treatment resulted in the formation of mesopores, as can be seen in pore size distribution (PSD) chart (Figure 1B, inset). For comparison purposes, the PSD for hierarchical zeolite $\beta$ obtained by caustic treatment is also presented [5].
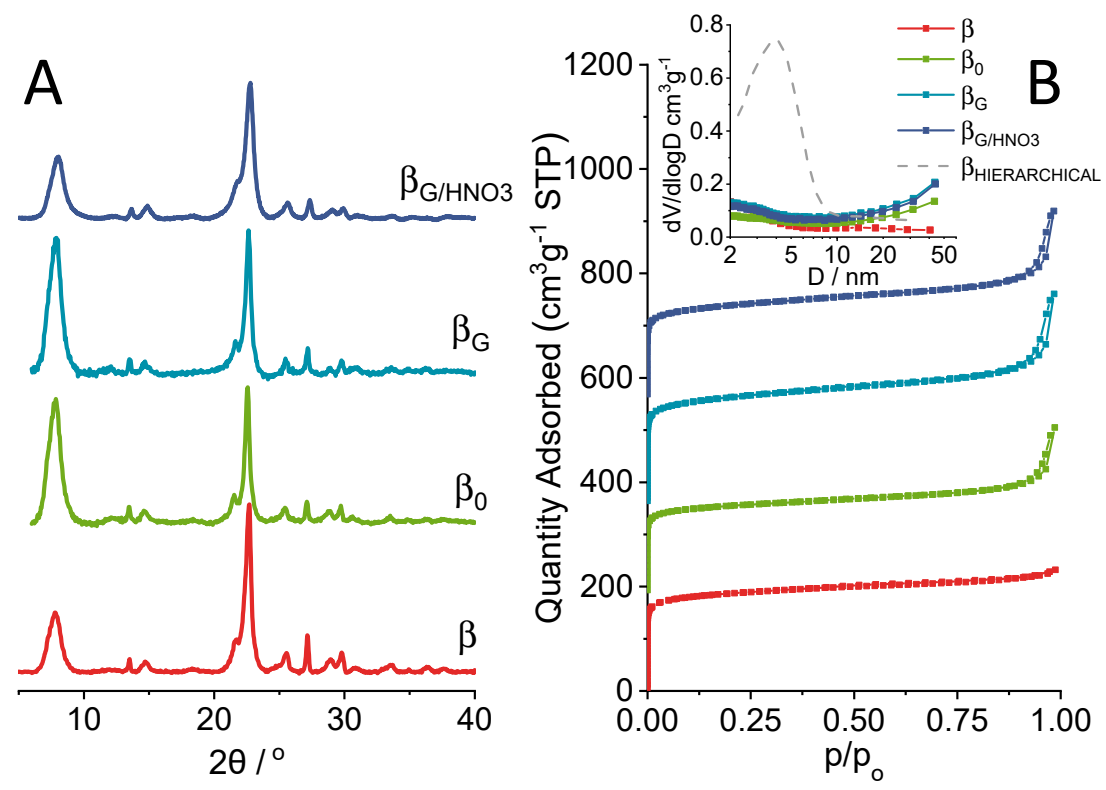

Figure 1. XRD patterns (A) and $\mathrm{N}_{2}$ adsorption-desorption isotherms with pore size distribution (inset)

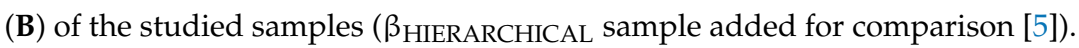


Table 1. Chemical composition and textural properties derived from $\mathrm{N}_{2}$ physisorption of the zeolites studied.

\begin{tabular}{ccccccc}
\hline \multirow{2}{*}{ material } & \multirow{2}{*}{ Si/Al ${ }^{\mathbf{a}}$} & $\mathbf{S}_{\text {BET }}{ }^{\mathbf{b}}$ & $\mathbf{S}_{\text {micro }}{ }^{\mathbf{c}}$ & $\mathbf{S}_{\text {EXT }}{ }^{\mathbf{d}}$ & $\mathbf{V}_{\text {micro }}{ }^{\mathbf{a}}$ & $\mathbf{V}_{\text {EXT }}{ }^{\mathbf{e}}$ \\
\hline$\beta^{3}$ & 22 & 567 & 523 & 44 & 0.18 & 0.06 \\
\hline$\beta_{0}$ & 19 & 667 & 535 & 134 & 0.19 & 0.11 \\
\hline$\beta_{\mathrm{G}}$ & 20 & 690 & 537 & 153 & 0.20 & 0.15 \\
\hline$\beta_{\mathrm{G} / \mathrm{HNO} 3}$ & 22 & 740 & 586 & 154 & 0.22 & 0.18 \\
\hline
\end{tabular}

a $\mathrm{Si} / \mathrm{Al}$ ratio obtained from chemical analysis (ICP); ${ }^{\text {c }}$ calculated via BET method with the recommendations of Rouquerol et al. [20]; ${ }^{\mathrm{c}}$ calculated from t-plot; ${ }^{\mathrm{d}}$ calculated as the difference between BET and $\mathrm{S}_{\text {micro }}{ }^{\mathrm{e}}$ calculated from $\mathrm{BHJ}$ model.

The commercial zeolite $\beta$ consisted of particles with a size of $200-400 \mathrm{~nm}$ (Figure 2). The $\beta_{0}$ zeolite prepared using the protozeolytic unit-based method possessed smaller crystals (100-200 nm), which undoubtedly indicates that the presence of more nucleation centers during synthesis leads to smaller particles of zeolite. Functionalization of protozeolytic units by an organosilane significantly changed the morphology of $\beta_{\mathrm{G}}$ sample. The agglomerated globular structures of 100-150 nm possessed a more uniform distribution of size. The small crystals covered those globular structures, as easily distinguishable in the STEM micrographs (Figure S1, Supplementary Materials). The acid treatment affected the particles size distribution by increasing the fraction of the particles with a size below $100 \mathrm{~nm}$, which slightly increased the external surface area and volume values $\left(\mathrm{S}_{\mathrm{EXT}}, \mathrm{V}_{\mathrm{EXT}}\right)$. The acid treatment of $\beta_{\mathrm{G}}$ also resulted in $\mathrm{Al}$ abundance differentiation in the $\beta_{\mathrm{G} / \mathrm{HNO}}$ sample. The transmission electron microscopy-based energy-dispersive X-ray (EDX) analysis of single zeolite crystals and ICP-OES elemental analysis showed the lowered content of $\mathrm{Al}(0.84 \mathrm{wt} . \%)$ with respect to non-leached zeolite $\beta_{\mathrm{G}}$ (1.25 wt.\%). Further distinction between changes in concentration of differently coordinated aluminum species was derived from pyridine and low-temperature $\mathrm{CO}$ adsorption followed by FTIR spectroscopy (Section 2.2).

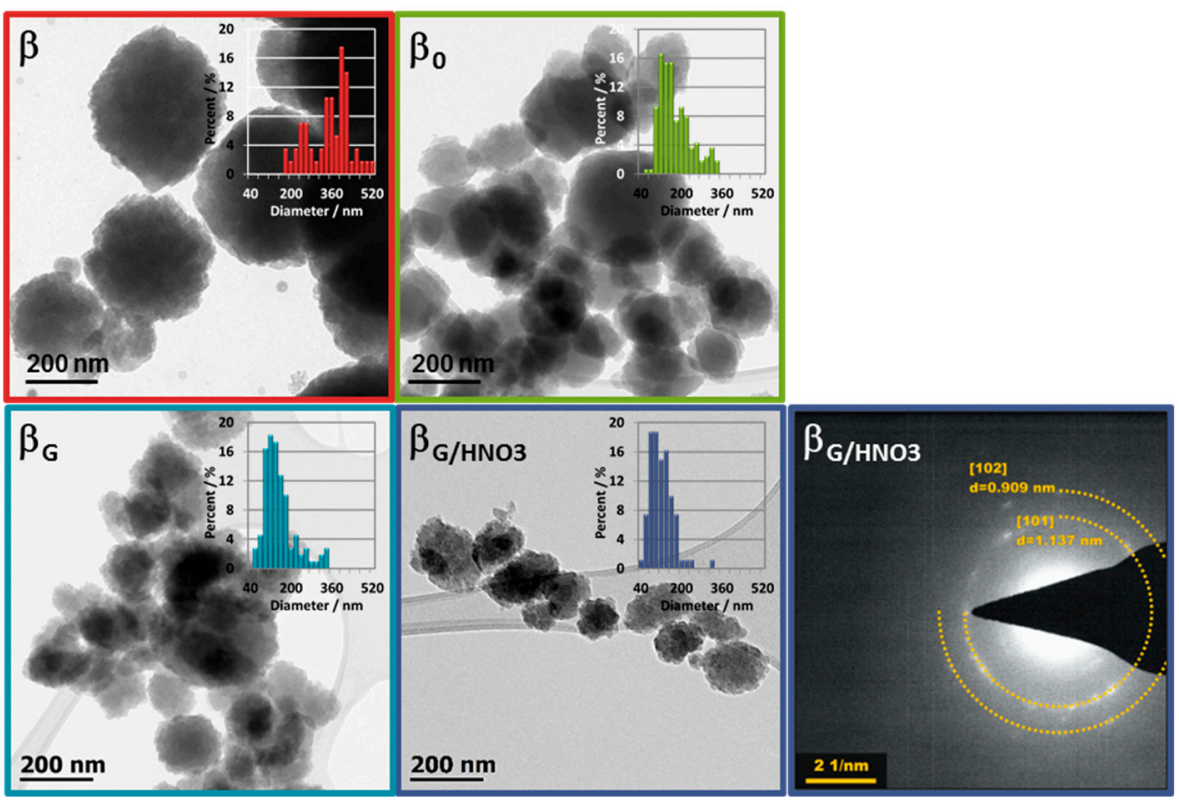

Figure 2. TEM micrographs of all studied samples and diffraction pattern of $\beta_{\mathrm{G} / \mathrm{HNO}}$ zeolite taken from the selected area. 


\subsection{Acidic Properties: Pyridine and Carbon Monoxide Sorption Studies}

In addition to specific sorption properties derived from the size and spatial arrangement of pores, the applicability of the zeolites is also ruled by their acidic properties. The acidic property is decisive especially in cracking reactions. Several methods were developed to follow the origin and concentration of both Brønsted and Lewis acid sites. Among them, FTIR spectroscopy, involving the use of probe molecules, is of the highest significance. Pyridine (Py) [21] is a suitable probe molecule for the quantitative analysis of surface acidity of medium and wide pore zeolites. The assessment of textural and acidic parameters influences, in an individual manner, the catalytic performance required to decouple the respective impacts. Pyridine adsorption FTIR experiments (Table 2) assessed, in qualitative and quantitative terms, the protonic (the $1545-\mathrm{cm}^{-1}$ band) and Lewis $\left(1455-1445-\mathrm{cm}^{-1}\right.$ bands) acidity (Figure 3A). The studied zeolites accommodated a comparable number of protonic sites. The total concentrations of acid sites $\left(C_{B}+C_{L}\right)$ determined by Py in all the zeolites matched well with the values of the $\mathrm{Al}$ content obtained from the chemical analysis (Table 2). The variations between the $\mathrm{Al}$ content and the acid site concentration did not exceed 15\%; thus, each $\mathrm{Al}$ atom was supposed to form either an acidic $\mathrm{Si}(\mathrm{OH}) \mathrm{Al}$ group or a Lewis acid site, both easily accessible to the Py molecule. Certain deviations in the number of the sites quantified by $\mathrm{Py}$ and $\mathrm{Al}$ atoms calculated from the zeolite composition may have originated from the presence of non-acidic Al-species detected in OH-groups FTIR spectra as the band at $3666 \mathrm{~cm}^{-1}$, albeit with negligible intensity (Figure 3B). It should be noted that the relatively high concentration of Lewis acid sites in all the zeolites $\beta$ resulted from the partial dealumination occurring during removal of the high amounts of SDAs (structure-directing agents). Treatment of zeolite $\beta_{\mathrm{G}}$ with an acidic solution led to the partial removal of Al species serving as Lewis acid sites; however, no perturbation in the number of protonic sites was observed.

Table 2. The amounts of $\mathrm{Al}$ derived from ICP analysis, the concentration of Brønsted $\left(\mathrm{C}_{\mathrm{B}}\right)$ and Lewis $\left(\mathrm{C}_{\mathrm{L}}\right)$ acid sites, and the acid strength of the $\mathrm{Si}(\mathrm{OH}) \mathrm{Al}$ groups $\Delta v(\mathrm{CO} \bullet \bullet \mathrm{OH})$.

\begin{tabular}{|c|c|c|c|c|c|c|}
\hline \multirow{2}{*}{ Material } & $\mathrm{Al}^{\mathrm{a}}$ & $\mathrm{C}_{\mathrm{B}}$ & $C_{L}$ & $C_{B}+C_{L}$ & $\mathrm{Py}_{450} / \mathrm{Py}_{170}$ & $\Delta v\left({ }_{\mathrm{CO} \bullet \bullet \circ \mathrm{OH}}\right)$ \\
\hline & $\left(\mu \mathrm{mol} \cdot \mathrm{g}^{-1}\right)$ & & $\left(\mu \mathrm{mol} \cdot \mathrm{g}^{-1}\right)$ & & & $\left(\mathrm{cm}^{-1}\right)$ \\
\hline$\beta$ & 675 & 395 & 220 & 615 & 0.80 & 309 \\
\hline$\beta_{0}$ & 762 & 405 & 236 & 641 & 0.84 & 321 \\
\hline$\beta_{G}$ & 756 & 398 & 230 & 628 & 0.86 & 324 \\
\hline$\beta_{\mathrm{G} / \mathrm{HNO} 3}$ & 670 & 390 & 124 & 534 & 0.90 & 330 \\
\hline
\end{tabular}

The acid strength of studied zeolites was determined based on Py thermo-desorption and low-temperature CO adsorption experiments followed by FTIR spectroscopy. The Py450/Py170 values (Py450, Py170 represent the $\mathrm{PyH}^{+}$ion band intensities upon the desorption at the temperatures indicated) (Table 2) clearly point out that the strength of protonic sites in all the protozeolytic unit-synthesized zeolites was higher than in the commercial material $\beta$. Additionally, carbon monoxide was applied to probe the strength of the $\mathrm{Si}(\mathrm{OH}) \mathrm{Al}$ acid sites. The significantly lower value of the proton affinity (PA) of carbon monoxide $\left(\mathrm{CO}, \mathrm{PA}=141.9 \mathrm{kcal} \cdot \mathrm{mol}^{-1}\right)$ than Py pyridine $\left(\mathrm{Py}, \mathrm{PA}=204 \mathrm{kcal} \cdot \mathrm{mol}^{-1}\right)[22,23]$ resulted in the interaction of $\mathrm{CO}$ with the $\mathrm{Si}(\mathrm{OH}) \mathrm{Al}$ groups via a weak $\mathrm{H}$-bond, thus leading to the formation of the $\mathrm{Si}\left(\mathrm{OH}^{\bullet \bullet} \mathrm{CO}\right) \mathrm{Al}$ adducts. Saturation of all protonic sites with carbon monoxide at $-130{ }^{\circ} \mathrm{C}$ resulted in the downshift of the IR band of the acidic $\mathrm{Si}(\mathrm{OH}) \mathrm{Al}$ hydroxyls due to their hydrogen bonding to $\mathrm{CO}$ molecules; therefore, the $\Delta v(\mathrm{CO} \bullet \bullet \cdot \mathrm{OH})$ can be taken as a measure of the acid strength. The commercial zeolite $\beta$ possessed the Brønsted sites of the lowest strength as documented by the lowest value of $\Delta v(\mathrm{CO} \bullet \bullet \mathrm{OH})$. The highest values $\Delta v(\mathrm{CO} \bullet \bullet \mathrm{OH})$ were observed for the zeolite $\beta_{\mathrm{G} / \mathrm{HNO}}$, i.e., the material with the highest value of micropore volume. The extraction of aluminum extra-framework material via acidic solution treatment resulted in a further upsurge of the acid strength of Si(OH)Al hydroxyls (Py450/Py170 and $\Delta v(\mathrm{CO} \bullet \bullet \mathrm{OH})$, Table 2). The contribution of the dispersion 
interaction between the small $\mathrm{CO}$ molecules and zeolite wall for the $\mathrm{Si}\left(\mathrm{OH}^{\bullet \bullet \bullet} \mathrm{CO}\right) \mathrm{Al}$ adsorption complexes can be assumed equal for all $\beta$ zeolites studied. As a result, the $\Delta v(\mathrm{CO} \bullet \bullet \mathrm{OH})$ values were independent of the dispersion contributions, and they strictly represent the trends in the acid strength alteration.
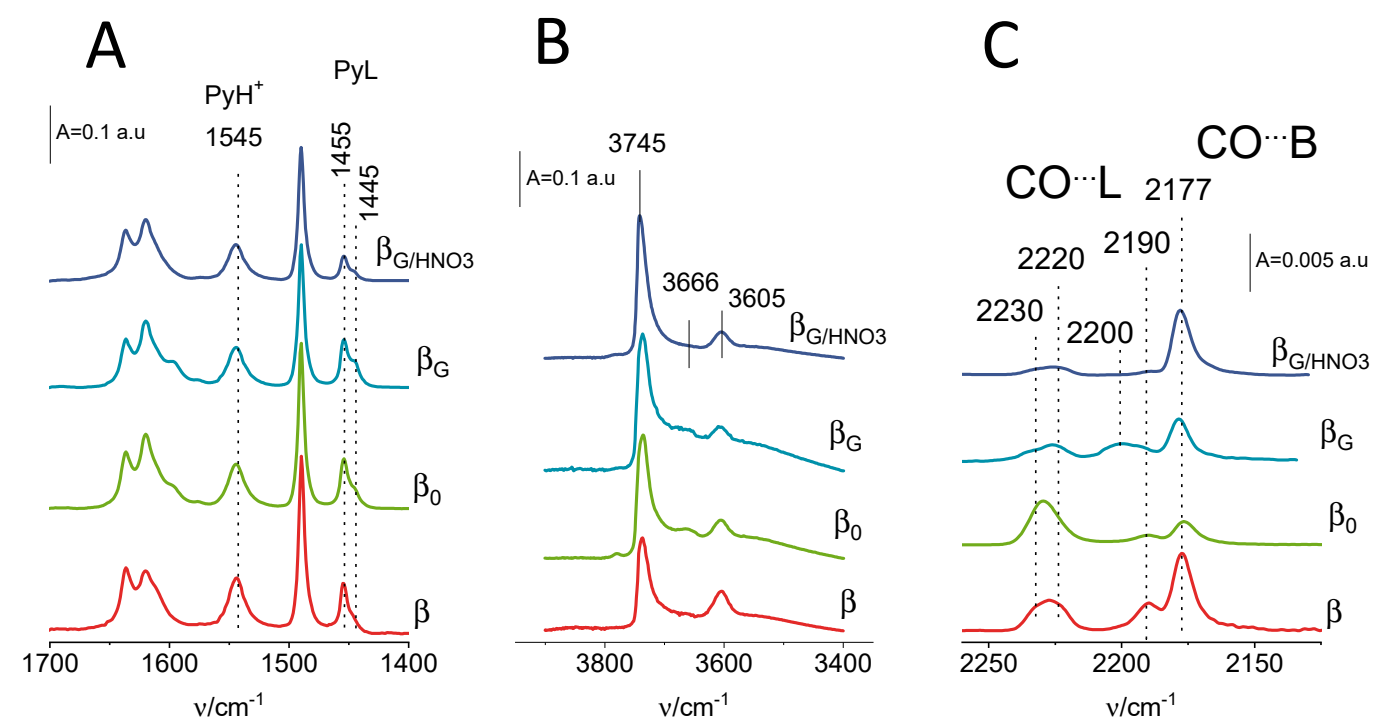

Figure 3. IR spectra of zeolites studied collected (A) during quantitative Py sorption studies, (B) in the region of $\mathrm{O}-\mathrm{H}$ stretching vibrations. and $(\mathbf{C})$ during the saturation of Lewis acid sites with carbon monoxide.

The differences in the speciation of Lewis acid sites was demonstrated by the presence of two PyL bands at 1445 and $1455 \mathrm{~cm}^{-1}$. From the weak intensity of the $1445-\mathrm{cm}^{-1}$ band, we can conclude the presence of a small population of the Lewis sites of low strength. The additional insight into the Lewis acid site nature was provided in the $\mathrm{CO}$ adsorption experiments, in which small doses were adsorbed up to the total saturation of all the Lewis acid sites, i.e., the maximum intensities of the bands in the 2250-2180- $\mathrm{cm}^{-1}$ frequency region and the appearance of the $2177-\mathrm{cm}^{-1}$ band of the $\mathrm{CO}$ interacting with Brønsted acid sites (Figure 3C). Numerous studies on zeolites $\beta$ focused on the role of the octahedrally coordinated aluminum species, distinguishing them as extra-framework- or framework-associated, depending on the aluminum's ability to reversibly change its coordination. The framework-associated octahedrally coordinated aluminum in protonic zeolites is created by partial hydrolysis of framework $\mathrm{Si}-\mathrm{O}-\mathrm{Al}$ bonds able to quantitatively revert to tetrahedral coordination when heating or ion-exchanging the zeolite to $\mathrm{Na}^{+}$or $\mathrm{NH}_{4}{ }^{+}$form [24-28]. The octahedrally coordinated aluminum species are believed to be present only in the case of proton-exchanged zeolites. Two close Brønsted acid sites are, therefore, needed to generate the defective site able to change the aluminum coordination into octahedral [29]. The Lewis acid sites in all the zeolites studied mostly originated from the dehydroxylation process (represented by the $\mathrm{CO}$ bands at 2230 and $2220 \mathrm{~cm}^{-1}$ ) and can be, therefore, considered as framework-associated three-fold coordinated aluminum atoms. The Al species represented by the $\mathrm{CO}$ bands at $2200-2190 \mathrm{~cm}^{-1}$ significantly populated only in $\beta_{\mathrm{G}}$ were attributed to extra-framework- and/or framework-associated octahedral species. This attribution is in good agreement with the observation that solely the latter species, as well as Al-OH species (represented by 3666- $\mathrm{cm}^{-1}$ bands, Figure 3B), turned out to be easily leached by acid treatment.

\subsection{Catalytic Performance: Thermogravimetric and Operando IR Studies}

The results of the LDPE catalytic cracking over zeolites studied are given in Figure 4, where the LDPE conversion is plotted as a function of temperature. The observed differences resulted from the properties inherent to zeolites, mainly textural and acidic features. The comparison of the 
temperature with $50 \%$ conversion $\left(\mathrm{T}_{50 \%}\right.$ ) for all the zeolites $\beta$ studied and pure LDPE shows clearly the advantage in the use of the zeolite catalysts. The cracking temperature progressively shifted to lower

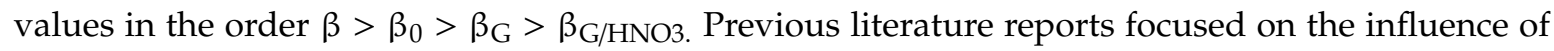
microporous features such as the internal cavity volume and the dimensionality of the pore structure on the product selectivity in cracking reactions [30]. Propane cracking was found to be facilitated on acid sites located in the eight-ring channels over the 12-ring ones of H-mordenite. This was related to partial confinement of the transition states within smaller pockets [31]. In contrast, protons located in less confined voids of ZSM-5, e.g., in the intersection of the channels, contributed to the increased cracking rate of $n$-butane because of their lesser confinement [25]. The obtained results show that the improved catalytic performance of zeolite $\beta_{\mathrm{G} / \mathrm{HNO}}$ originated from the highly microcrystalline structure free of extra-framework Al species. The improvement in microenvironment properties was not only beneficial in terms of meaningfully enhanced confined sorption; the strength of the protonic sites was also significantly increased (Table 2). The correlation between catalytic activity in polyethylene decomposition $\left(\mathrm{T}_{50 \%}\right)$ and the features inherent to the microporous environment, i.e., the strength of sites expressed by $\Delta v(\mathrm{CO} \bullet \bullet \mathrm{OH})$, as well as the $\mathrm{V}_{\text {micro }}$ values (Figure $4 \mathrm{~B}$ ), clearly pointed to the benefits provided by microporous characteristics. The results discussed above are in line with previous reports [32] on the cracking of low-density (LDPE) and high-density polyethylene (HDPE). High external surface area is of secondary importance when considering 12-ring zeolites as reported for hierarchical zeolites $\beta$ obtained through base-leaching [32]. If quenching the microporous characteristics, i.e., the number of voids inducing the confinement effect, the catalytic ability can be significantly reduced. Derouane et al. [33] pointed out that the interaction between the adsorbate molecule and the zeolite surface is the strongest when the radius of the molecule and the surface curvature are comparable. The enhanced interaction leads to increased concentration of reactants in the neighborhood of the acid sites. The 3D micropore structure of the zeolite and its effect on sorption equilibrium have an additional great impact on the reaction rate, especially when the sorption energetics are magnified by the surface curvature [33]. Jones et al. [34], on the basis of the ensemble-averaged transition state energy determined for MFI, BEA, mordenite, ferrierite, faujasite, andchabazite, concluded that all these structures stabilize transition states with electrostatic interactions to similar extents. Because of the deprotonation energy, values do not depend on the proton acceptor; they provide an acid strength scale that is independent of the reacting or adsorbing molecules involved. Consequently, the authors ascribed the differences in the catalytic performance to the diversity of zeolite void shapes and sizes that confine transition states and reactive intermediates to different extents. The same shape and size of the confining voids in the zeolites $\beta$ studied give rise to the same adsorption adducts. Then, the differences in the $\mathrm{Si}(\mathrm{OH}) \mathrm{Al}$ hydroxyls strength should be considered as of the primary importance. Diffusional restrictions for the LDPE chains, almost identical due to the same textural parameters, affect the catalytic cracking to a lesser extent than the strength of the sites located in the internal voids. The catalytic reactivity of Brønsted acid sites confined in zeolites is determined not only by their intrinsic chemistry but also by the specific topologic features of the zeolite matrix incorporating them. The proton location should be considered as a factor influencing the diversity in their catalytic behavior [35]. Furthermore, their spatial proximity can also substantially affect the properties of confined catalytic sites; adjacent Brønsted acid sites significantly enable central cracking over the terminal because of higher van der Waals stabilization energies [36]. 



Figure 4. (A) Conversion curves of low-density polyethylene (LDPE) cracking on studied zeolites. The thermal cracking of LDPE is included for comparison. (B) The correlation between catalytic activity in polyethylene decomposition (temperature for 50\% conversion) and the strength of sites (open symbols) and $\mathrm{V}_{\text {micro }}$ (solid symbols).

The role of the strength of protonic sites can be visualized in Figure 4B where an additional decrease in conversion temperature was observed for the $\beta_{\mathrm{G} / \mathrm{HNO} 3}$ catalyst accommodating the protons of the strength increased by extra-framework material extraction while preserving the Al Lewis sites of high strength. The catalytic cracking reaction of LDPE on studied zeolites was followed in FTIR operando studies with GC-MS analysis of the resulting products (Figure 5). The FTIR/GC-MS operando studies were performed at $230^{\circ} \mathrm{C}$. For the LDPE cracking, the decisive factors were the density and the strength of acid sites of the catalysts, as polymer fragments were able to diffuse through all the system of channels. In other words, after preliminary cracking, the polymer fragments must diffuse through a micropore system to reach active sites with strong enough acidity for cracking these relatively refractory molecules. The speciation of acid sites governs the selectivity of the cracking process. The quantification of the reaction products by GC-MS showed that the catalyst $\beta_{\mathrm{G} / \mathrm{HNO}}$ predominantly yielded paraffin (Figure $5 \mathrm{~A}$ ). Lewis acid sites on the catalyst abstracted a hydride from the alkane and produced alkenes. The lower concentration of Lewis acid sites in $\beta_{\mathrm{G} / \mathrm{HNO}}$ reduced the dehydrogenation of alkanes, thereby providing a highly paraffinic fraction. The setting of $\mathrm{Al}$ atoms and their spatial proximity also affect the adsorption selectivity and, therefore, the selectivity of the overall catalytic process [36,37]. Adjacent Brønsted acid sites favor cracking over dehydrogenation, as well as central cracking over terminal cracking. However, the unique feature of zeolites $\beta$ are a poor representation of the single $\mathrm{Al}$ atoms in favor of the close unpaired $\mathrm{Al}$ atom. In zeolite $\beta$, the concentration of $\mathrm{Al}$ pairs can vary between $40 \%$ and $65 \%$ of the $\mathrm{Al}$ atoms (for $\mathrm{Si} / \mathrm{Al}<18$ ) [38]. Therefore, adjacent $\mathrm{Al}$ atoms, i.e., both $\mathrm{Al}$ atoms in the pairs and closed unpaired $\mathrm{Al}$ atoms in zeolite $\beta$, can synergistically enhance the adsorption of central $\mathrm{C}-\mathrm{C}$ bonds and their cracking. The bimolecular hydrogen transfer reactions require adjacent acid sites to facilitate interaction between two adsorbed molecules. These reactions also result in decreased olefin production. The less extensive recracking rate in $\beta_{\mathrm{G} / \mathrm{HNO}}$ can be assigned to the facilitated diffusion of reagents due to purifying the zeolite channels from extra-framework species (EFAL). In other words, the presence of bulkier EFAL moieties in the zeolite micropores can benefit the geometrical changes in the zeolite voids and finally impact the more efficient stabilization of the reaction intermediates and/or transition states. This strongest interaction between the adsorbate and the zeolite surface can rule both the selectivity and the activity of the catalyst [39]. Furthermore, the enhanced interaction leads to increased concentration of reactants in the neighborhood of the acid sites. 


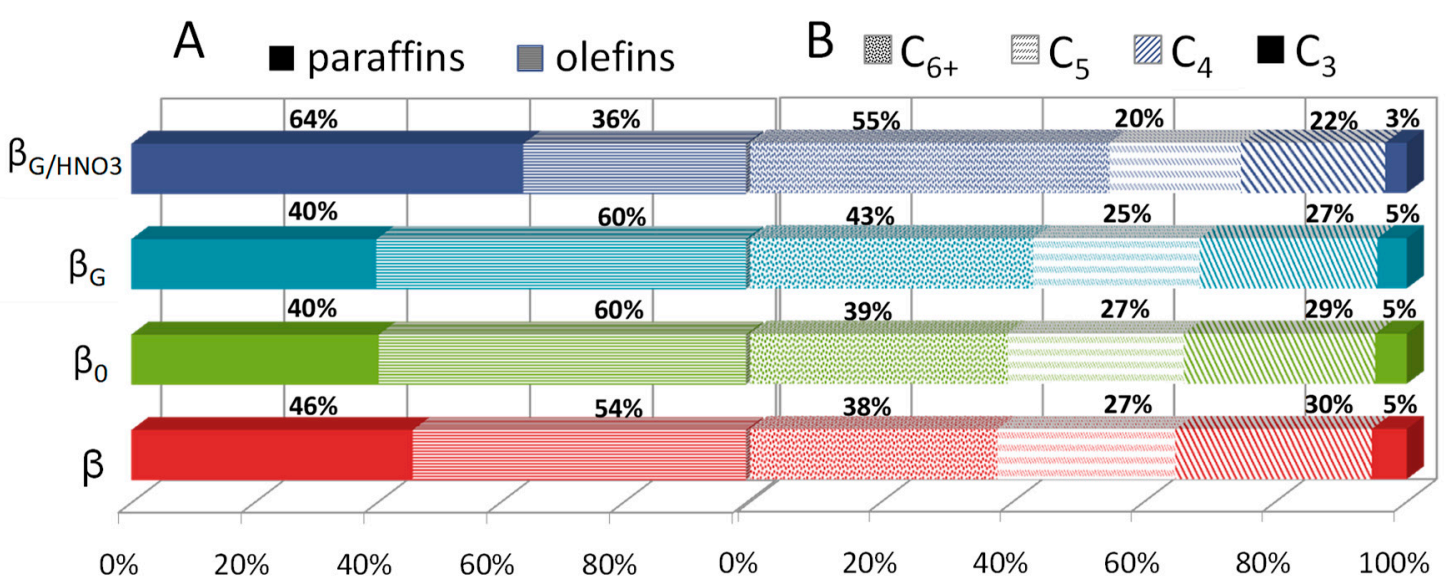

Figure 5. Distribution of paraffinic (solid symbols) and olefinic (pattern symbol) products (A) and the selectivity of the LDPE cracking over zeolites Beta studied (B).

Cracking of large polymer fragments on the external surface of the catalyst is associated with oligomerization, cyclization, and hydrogen transfer reactions. Carbonaceous deposits are generally known to induce catalytic deactivation of zeolites. The reaction followed by operando FTIR/GC-MS studies allowed for simultaneous monitoring of the catalytic performance and the build-up of carbonaceous deposits on the surface. The lower amount of extra-framework Lewis acid species resulted in increased coke deposit formation. The coke deposit evolution was followed by the $1590-\mathrm{cm}^{-1}$ band assigned to of $\mathrm{C}=\mathrm{C}$ band of aromatic compounds that cannot be desorbed [40] (Figure 6). Upon cracking of the LDPE, the disappearance of $1450-$ and $1375-\mathrm{cm}^{-1}$ bands $\left(\mathrm{CH}_{3}-\right)$ accompanied by the development of a $1590-\mathrm{cm}^{-1}$ band on one-dimensional (1D) FTIR was observed (Figure 6A). The two-dimensional (2D) correlation analysis of FTIR spectroscopy results (Figure 6B) showed a negative cross-peak between these bands in the synchronous maps. The comparison of the 1D FTIR spectra of the $\beta_{\mathrm{G} / \mathrm{HNO}}$ and $\beta_{\mathrm{G}}$ spent catalysts within the $1300-1700-\mathrm{cm}^{-1}$ region (Figure $6 \mathrm{~A}$ ) clearly shows that the new spectral features at $1475 \mathrm{~cm}^{-1}$ related to the alkyl aromatics $[40,41]$ arose solely for zeolite $\beta_{\mathrm{G} / \mathrm{HNO} 3}$. The results show that the micropores of $\beta_{\mathrm{G} / \mathrm{HNO} 3}$ free of extra-framework species together with Brønsted sites of high strength enhanced bimolecular reactions, condensation, and cyclization, yielding more aromatic carbonaceous species. The diffusivity of the cracked linear LDPE chains should be reflected in their concentration changes as a time function inside the micropores. Therefore, hexane was used as a model compound and its diffusivity was measured by rapid scan FTIR spectroscopy by collecting one spectrum every $0.2 \mathrm{~s}$. The sorption of hexane was followed using the $1450-\mathrm{cm}^{-1}$ band intensity changes upon sorption at room temperature (RT) and $100{ }^{\circ} \mathrm{C}$ and $30 \mathrm{mbar}$ of partial pressure. The values of the $\mathrm{Q}_{\mathrm{t}} / \mathrm{Q}_{\mathrm{e}}$ ratio (where $\mathrm{Q}_{\mathrm{t}}$ represents uptake at time $\mathrm{t}$ and uptake after equilibration $Q_{e}$ ) were plotted versus the square root of the time (Figure 7). In-line monitoring of hexane adsorption confirmed the same diffusivity of hexane in both $\beta_{\mathrm{G} / \mathrm{HNO} 3}$ and $\beta_{\mathrm{G}}$. With regard to the uptake of hexane, the model compound of linear products of the LDPE chain cracking was the same for both zeolites, as the textural features did not affect the hydrogen transfer and oligomerization reactions. Therefore, the yield of the aforementioned processes was ruled by the strength of Brønsted acid sites. 


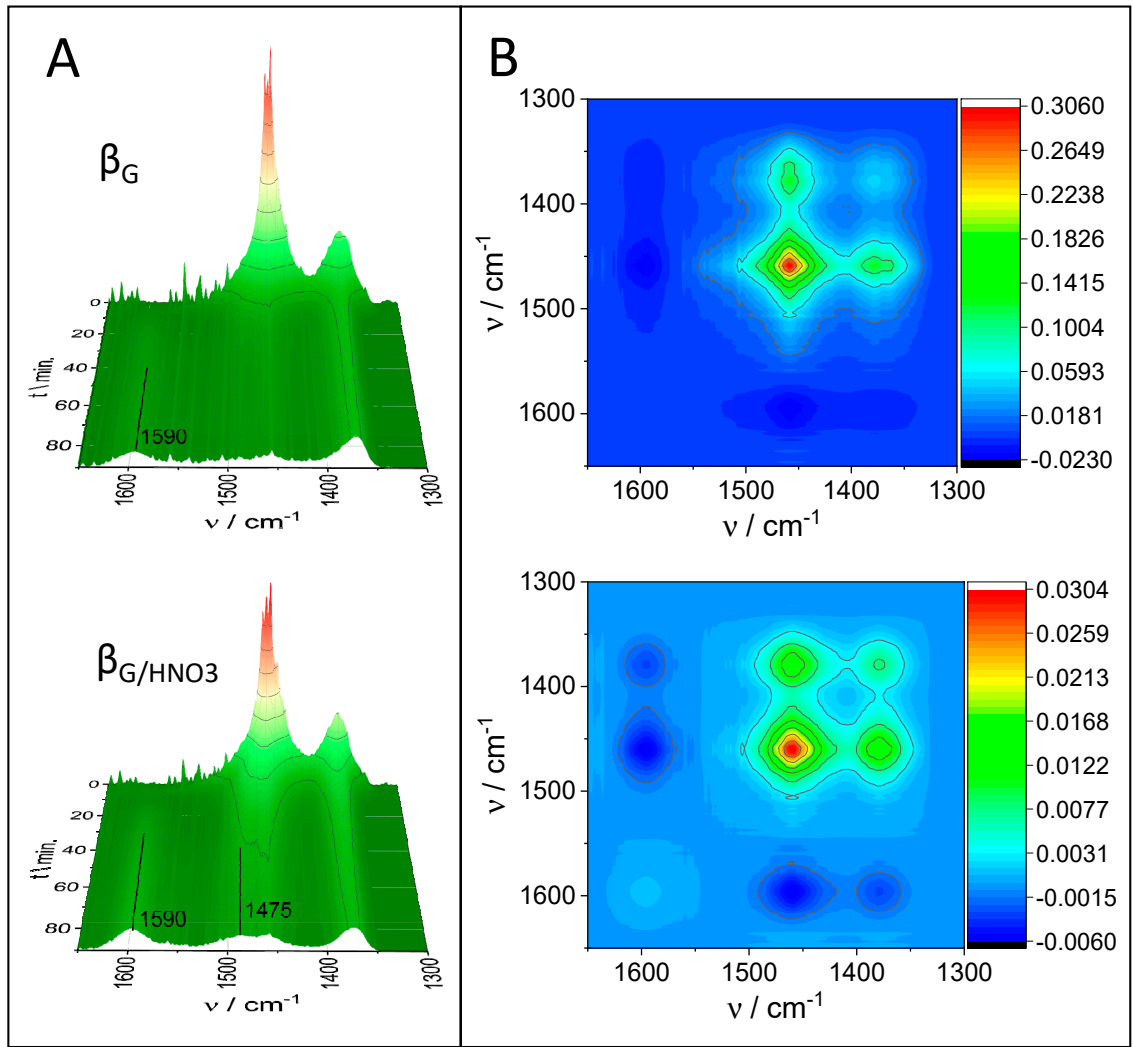

Figure 6. (A) Time-resolved FTIR spectra of LDPE cracking over zeolites $\beta_{G} / \mathrm{HNO}$ and $\beta_{\mathrm{G}}$ during $80 \mathrm{~min}$ of the reaction. (B) The synchronous correlation two-dimensional (2D) spectra representing the coke residue formation in zeolites $\beta_{\mathrm{G} / \mathrm{HNO}}$ and $\beta_{\mathrm{G}}$.

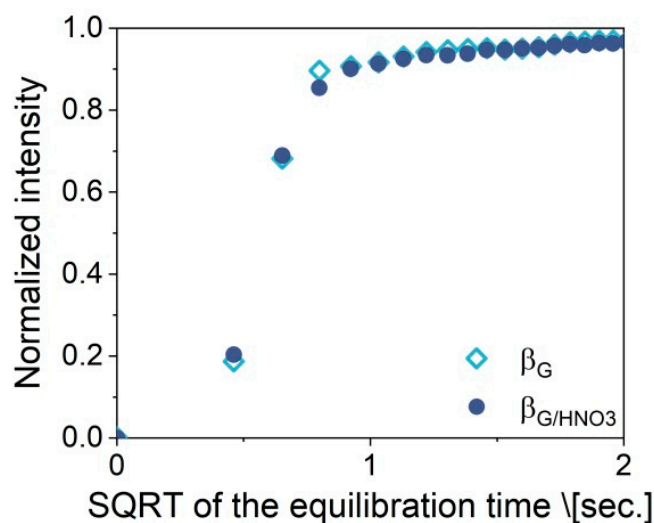

Figure 7. Dependence of the normalized intensity of $1450-\mathrm{cm}^{-1}$ band of hexane on the square root of time for zeolites $\beta_{\mathrm{G} / \mathrm{HNO} 3}$ and $\beta_{\mathrm{G}}$. Hexane was sorbed at $100{ }^{\circ} \mathrm{C}$.

\section{Materials and Methods}

\subsection{Materials}

\subsubsection{Preparation of Beta Seeds}

The zeolite $\beta$ seeds were prepared from the mixture with a molar composition of $\mathrm{SiO}_{2}: 0.02 \mathrm{Al}_{2} \mathrm{O}_{3}$ : $0.028 \mathrm{Na}_{2} \mathrm{O}$ : $0.6 \mathrm{TEAOH}: 0.2 \mathrm{HCl}: 20 \mathrm{H}_{2} \mathrm{O}$. In a typical synthesis, $14.7 \mathrm{~cm}^{3}$ of $25 \%$ tetraethylammonium hydroxide (35\% TEAOH, Sigma-Aldrich, Grajewo, Poland) was mixed with $2.25 \mathrm{~cm}^{3}$ of $3.70 \mathrm{M} \mathrm{HCl}$ (37\%, POCh, Gliwice, Poland). Then, $2.5 \mathrm{~g}$ of fumed silica (Sigma-Aldrich, Grajewo, Poland) was added under vigorous stirring. After $30 \mathrm{~min}, 0.1906 \mathrm{~g}$ of sodium aluminate $\left(\mathrm{NaAlO}_{2}\right.$, Riedel-de-Haën, 
Torun, Poland) dissolved in $2.9 \mathrm{~cm}^{3}$ water was added, and the reaction mixture was stirred for the next $30 \mathrm{~min}$. The obtained gel was aged at $150{ }^{\circ} \mathrm{C}$ for $22 \mathrm{~h}$ under static conditions, yielding the zeolite ßprecursor.

\subsubsection{Functionalization: Zeolite $\beta_{G}$}

The seed solution was used in the functionalization of zeolite seeds by an organosilane. The produced seeds were functionalized with (3-glycidyloxypropyl)trimethoxysilane (GLYMO) (Innosil, Poznan, Poland), which was used in a molar percentage of $5 \%$ relative to the total amount of silicon in the seed gel. The functionalization of $\beta$ seeds with the organosilane took place under reflux at $90{ }^{\circ} \mathrm{C}$, for $6 \mathrm{~h}$, with stirring.

The crystallization step was followed by hydrothermal treatment in fully Teflon-lined autoclaves at $150{ }^{\circ} \mathrm{C}$ for three days under static conditions. The obtained materials were filtered, washed with water, and dried in air at ambient temperature. The template of as-synthesized samples was removed by calcination at $550{ }^{\circ} \mathrm{C}$ (heating rate of $1{ }^{\circ} \mathrm{C} \cdot \mathrm{min}^{-1}$ ) for $8 \mathrm{~h}$ in air.

The protozeolytic microporous $\beta$ material was synthesized according to the procedure described above without the modification step. The $\beta$ seed mixture after cooling (without opening the autoclave) was crystallized in the same way as the modified samples. The sample after crystallization and calcination was denoted as $\beta_{0}$.

Calcined samples were converted to their ammonium form by four-fold ammonium ion exchange with $0.5 \mathrm{M} \mathrm{NH}_{4} \mathrm{NO}_{3}$ at $60^{\circ} \mathrm{C}$ for $1 \mathrm{~h}$.

The commercial zeolite $\mathrm{NH}_{4}$ Beta $(\mathrm{Si} / \mathrm{Al}=22$, Zeolyst, Kansas City, KS, USA, CP814C) was denoted as $\beta$.

The most active catalyst $\beta_{\mathrm{G}}(250 \mathrm{mg})$ was leached with $0.05 \mathrm{M} \mathrm{HNO}_{3}$ solution $\left(9 \mathrm{~cm}^{3}\right)$ to extract extra-framework $\mathrm{Al}$ Lewis acid sites from the microporous environment.

Finally, the zeolites were filtrated, washed, dried at room temperature, and calcined at $550{ }^{\circ} \mathrm{C}$ for $5 \mathrm{~h}$ with a heating rate of $2{ }^{\circ} \mathrm{C} \cdot \mathrm{min}^{-1}$, in order to obtain the active proton form.

The low-density polyethylene (LDPE) was supplied by Alfa Aesar (Product No.: 42607, Lot No.: P28D047).

\subsection{Methods}

Elemental Si and $\mathrm{Al}$ concentrations in the materials were determined by the ICP-OES method with an Optima 2100DV (PerkinElmer, Krakow, Poland) spectrometer. The zeolite sample (80-100 mg) was digested with $\mathrm{HCl}\left(4 \mathrm{~cm}^{3}, 35 \%\right)$ and $\mathrm{HF}\left(0.4 \mathrm{~cm}^{3}, 48 \%\right)$. The final weight of the solution was adjusted with deionized distilled water. Wide-angle XRD patterns were obtained with a Rigaku Multiflex diffractometer equipped with $\mathrm{Cu} \mathrm{K} \alpha$ radiation $(40 \mathrm{kV}, 40 \mathrm{~mA})$. Nitrogen sorption measurements at $-196{ }^{\circ} \mathrm{C}$ were performed on a Quantachrome Autosorb-1-MP gas sorption apparatus. Prior to the measurements, all samples were degassed under high vacuum $\left(10^{-5} \mathrm{mbar}\right)$ at $350{ }^{\circ} \mathrm{C}$ for $16 \mathrm{~h}$. The micropore volume was calculated based on the $t$-plot method. The apparent specific surface area was determined according to Brunauer-Emmet-Teller (BET) method considering the recommendations of Rouquerol et al. [17]. The pore size distribution and pore volume $\left(\mathrm{V}_{\mathrm{EXT}}\right.$, range between 1.7 and $30 \mathrm{~nm}$ ) were calculated via the Barrett-Joyner-Halenda (BJH) model using the adsorption branch [42]. Transmission electron microscopy (TEM) pictures were carried out using a Tecnai Osiris microscope (FEI) with an X-FEG Schottky field emitter operated at $200 \mathrm{kV}$. Scanning transmission electron microscopy (STEM) images were performed using a high-angle annular dark-field (HAADF) detector. The materials were dropped onto a holey carbon film supported on a copper grid (Agar Scientific, 300 mesh). Prior to FTIR studies, the materials were pressed into the form of self-supporting discs (ca. $10 \mathrm{mg} / \mathrm{cm}^{2}$ ) and pre-treated in situ in a custom-made quartz IR cell at $500{ }^{\circ} \mathrm{C}$ under vacuum conditions $\left(10^{-5}\right.$ mbar) for $1 \mathrm{~h}$. The spectra were recorded with a resolution of $2 \mathrm{~cm}^{-1}$ with a Vertex 70 spectrometer (Bruker, Poznan Poland) equipped with an MCT detector. All the spectra presented in this work were normalized to $10 \mathrm{mg}$ of sample. The sorption of CO (PRAXAIR, 9.5) was performed at $-100{ }^{\circ} \mathrm{C}$ up 
to the total saturation of the Lewis acid sites, up to maximum intensities of the 2230-2220- $\mathrm{cm}^{-1}$ and $2190-\mathrm{cm}^{-1}$ bands, and the appearance of the bands of CO bonded to Brønsted acid sites $\left(2175 \mathrm{~cm}^{-1}\right)$. The total concentrations of Brønsted and Lewis acid sites were determined from quantitative IR studies of pyridine (Py) sorption ( $\geq 99.8 \%$, Sigma-Aldrich Grajewo, Poland) $[43,44]$. The quantitative procedure involves the Py-gas sorption at $170{ }^{\circ} \mathrm{C}$ in an amount sufficient to neutralize all acid, followed by the desorption at the same temperature to remove the gaseous and physisorbed Py molecules. The band intensities in the latter spectrum were used to calculate the total concentration of Brønsted and Lewis sites, using the intensities (band height) of the $1545-\mathrm{cm}^{-1}$ band of pyridinium ions $\left(\mathrm{PyH}^{+}\right)$and the $1450-\mathrm{cm}^{-1}$ band of Py coordinatively bonded to Lewis sites (PyL). The following absorption coefficients were applied: $0.07 \mathrm{~cm}^{2} \cdot \mu \mathrm{mol}^{-1}$ for the $1545-\mathrm{cm}^{-1}$ band of pyridinium ion $\left(\mathrm{PyH}^{+}\right)$and $0.10 \mathrm{~cm}^{2} \cdot \mu \mathrm{mol}^{-1}$ for the $1450-\mathrm{cm}^{-1}$ band of pyridine coordinatively bonded to Lewis sites (PyL). The low-density polyethylene (LDPE) decomposition was studied in an operando system connected to a flow set-up. The self-supporting wafers (ca. $5.5-6 \mathrm{mg} / \mathrm{cm}^{2}$ ) prepared by mixing of the zeolitic catalyst with LDPE $(1: 1)$ were placed in a custom-made IR quartz gas cell of $1-\mathrm{cm}^{3}$ volume. This IR reactor cell enables the simultaneous analysis of the gas phase and the catalytic surface under operating conditions. The nitrogen used as the carrier gas $(30 \mathrm{~mL} / \mathrm{min})$ was introduced into the $1 / 16$ lines (heated at $110^{\circ} \mathrm{C}$ ). Time-resolved IR spectra were collected with a Vertex 70 Bruker FTIR spectrometer, equipped with MCT detector. The scanner velocity of $80 \mathrm{kHz}$ allowed for the accumulation of one spectrum (100 scans) every $0.5 \mathrm{~min}$. The spectral resolution was $2 \mathrm{~cm}^{-1}$. The experiments were carried out at atmospheric pressure. The analysis of the species formed during polyethylene decomposition was supported by IR gas cell (PIKE, Madison, WI, USA) and gas chromatography (Agilent, Warsaw, Poland). The analysis was carried out at $230{ }^{\circ} \mathrm{C}$ up to total LDPE decomposition. The 2D COS plots were obtained with the use of OPUS 3D software from Bruker Optics and OriginPro9.1.

The catalytic cracking of LDPE was evaluated by thermogravimetric analysis in a PerkinElmer Pyris 1 analyzer (PerkinElmer, Krakow, Poland). A stock mixture of the ground polymer and the zeolite powder was prepared in a ratio of polymer-zeolite $=3: 1$; this was prepared by intimately mixing in an Agatha mortar. A certain portion of the mixture (typically 5-10 mg) was loaded in a 70- $\mu \mathrm{L} \alpha-\mathrm{Al}_{2} \mathrm{O}_{3}$ crucible and weighted with a five-digit Mettler Toledo balance before the analysis. The sample was placed in the furnace, the analytic gas was switched on, and the temperature was raised from 30 to $600{ }^{\circ} \mathrm{C}$ at a heating rate of $5{ }^{\circ} \mathrm{C} / \mathrm{min}$ under a nitrogen flow of $80 \mathrm{~mL} / \mathrm{min}$ STP. The conversion was calculated by deducting the catalyst weight and moisture content. The coke content of spent catalysts was measured in TG experiments where the temperature was raised to $800{ }^{\circ} \mathrm{C}$, with a rate of $10^{\circ} \mathrm{C} / \mathrm{min}$, and in synthetic airflow $(80 \mathrm{~mL} / \mathrm{min})$. The amount of coke for each sample did not exceed $3.7 \%$ and was included in the conversion values.

\section{Conclusions}

The accumulation of high-strength $\mathrm{Si}(\mathrm{OH}) \mathrm{Al}$ sites in zeolite $\beta$ in a well-developed microporous environment benefited the reduction of maximum polymer decomposition temperature. The individual effects of textural parameters and acidity on the catalytic performance were decoupled to present the respective impacts. Through strategic comparison of purely microporous zeolites with tuned microporous characteristics, we showed that the catalytic cracking of LDPE is dominated by the acidic feature inherent to the microporous 12-ring pore system. The interplay between activity, selectivity, and stability in microporous zeolites $\beta$ can be optimized by relatively simple bottom-up synthesis modifications. Well-developed microporous characteristics and micropores free of extra-framework material assure the presence of the $\mathrm{Si}(\mathrm{OH}) \mathrm{Al}$ groups of high strength. Among catalysts of the same structure, whereby the impact of hydrocarbon and carbocation adsorption energies can be neglected, the differences in acid strength are actually relevant for catalytic reactivity.

Supplementary Materials: The following are available online: Figure S1: TEM/STEM micrographs. 
Author Contributions: K.G.-M. conceptualized, planned, and supervised the experiments. E.J. synthesized the zeolites studied and carried out the preliminary characterization. K.P. undertook the characterization of materials with the FTIR of probe molecules and operando studies and assisted in the interpretation of the results and preparing the manuscript. K.A.T. assisted in the interpretation of the spectroscopic results. D.M. carried out the thermogravimetric experiments. K.G.-M. wrote the manuscript. All authors read and agreed to the published version of the manuscript.

Funding: The work was financed by Grant No. 2017/27/B/ST5/00191 from the National Science Center, Poland.

Conflicts of Interest: The authors declare no conflicts of interest. The funders had no role in the design of the study; in the collection, analyses, or interpretation of data; in the writing of the manuscript, or in the decision to publish the results.

\section{References}

1. Camblor, M.A.; Corma, A.; Valencia, S. Spontaneous nucleation and growth of pure silica zeolite- $\beta$ free of connectivity defects. Chem. Commun. 1996, 2365-2366. [CrossRef]

2. Borade, R.B.; Clearfield, A. Preparation of aluminum-rich Beta zeolite. Microporous Mater. 1996, 5, $289-297$. [CrossRef]

3. Vaudry, F.; di Renzo, F.; Espiau, P.; Fajula, F.; Schulz, P. Aluminum-rich zeolite beta. Zeolites 1997, 19, $253-258$. [CrossRef]

4. Treacy, M.M.J.; Newsam, J.M. Two new three-dimensional twelve-ring zeolite frameworks of which zeolite beta is a disordered intergrowth. Nature 1988, 332, 249-251. [CrossRef]

5. Tarach, K.; Góra-Marek, K.; Tekla, J.; Brylewska, K.; Datka, J.; Mlekodaj, K.; Makowski, W.; López, M.C.I.; Triguero, J.M.; Rey, F. Catalytic cracking performance of alkaline-treated zeolite Beta in the terms of acid sites properties and their accessibility. J. Catal. 2014, 312, 46-57. [CrossRef]

6. Philippou, A.; Anderson, M.W. Solid-state NMR investigation of n-heptane cracking over zeolite beta. J. Catal. 1996, 158, 385-401. [CrossRef]

7. Taufiqurrahmi, N.; Mohamed, A.R.; Bhatia, S. Deactivation and coke combustion studies of nanocrystalline zeolite beta in catalytic cracking of used palm oil. Chem. Eng. J. 2010, 163, 413-421. [CrossRef]

8. Ramos, M.J.; de Lucas, A.; Jiménez, V.; Sánchez, P.; Valverde, J.L. Hydroisomerization of different refinery naphtha streams by using a beta zeolite catalyst. Fuel Process. Technol. 2008, 89, 721-727. [CrossRef]

9. Chica, A.; Corma, A. Comparison of large pore zeolites for n-octane hydroisomerization: Activity, selectivity and kinetic features. Chem. -Ing. -Tech. 2007, 79, 857-870. [CrossRef]

10. Sridevi, U.; Bokade, V.V.; Satyanarayana, C.V.V.; Rao, B.S.; Pradhan, N.C.; Rao, B.K.B. Kinetics of propylation of benzene over H-beta and SAPO-5 catalysts: A comparison. J. Mol. Catal. A Chem. 2002, 181, 257-262. [CrossRef]

11. Zhang, H.; Dai, B.; Wang, X.; Xu, L.; Zhu, M. Hydrochlorination of acetylene to vinyl chloride monomer over bimetallic Au-La/SAC catalysts. J. Ind. Eng. Chem. 2012, 18, 49-54. [CrossRef]

12. Siffert, S.; Gaillard, L.; Su, B.L. Alkylation of benzene by propene on a series of Beta zeolites: Toward a better understanding of the mechanisms. J. Mol. Catal. A Chem. 2000, 153, 267-279. [CrossRef]

13. Aguado, J.; Serrano, D.P.; Escola, J.M.; Garagorri, E.; Fernández, J.A. Catalytic conversion of polyolefins into fuels over zeolite beta. Polym. Degrad. Stab. 2000, 69, 11-16. [CrossRef]

14. Manos, G.; Garforth, A.; Dwyer, J. Catalytic degradation of high-density polyethylene over different zeolitic structures. Ind. Eng. Chem. Res. 2000, 39, 1198-1202. [CrossRef]

15. Liu, C.; Tranca, I.; van Santen, R.A.; Hensen, E.J.M.; Pidko, E.A. Scaling Relations for Acidity and Reactivity of Zeolites. J. Phys. Chem. C 2017, 121, 23520-23530. [CrossRef]

16. Van Oers, C.J.; Kurttepeli, M.; Mertens, M.; Bals, S.; Meynen, V.; Coo, P. Zeolite $\beta$ nanoparticles based bimodal structures: Mechanism and tuning of the porosity and zeolitic properties. Microporous Mesoporous Mater. 2014, 185, 204-212. [CrossRef]

17. Grecco, S.d.F.; de Carvalho, D.R.; Zandonai, C.H.; Fernandes-Machado, N.R.C.; Lião, L.M.; Urquieta-González, E.A.; Rangel, M.d.C. Catalytic cracking of crude soybean oil on Beta nanozeolites. J. Mol. Catal. A Chem. 2016, 422, 89-102. [CrossRef]

18. Huang, J.; Li, G.; Wu, S.; Wang, H.; Xing, L.; Song, K.; Wu, T.; Kan, Q. Synthesis, characterization and catalytic activity of cubic Ia3d and hexagonal p6mm mesoporous aluminosilicates with enhanced acidity. J. Mater. Chem. 2005, 15, 1055-1060. [CrossRef] 
19. Campelo, J.M.; Luna, D.; Luque, R.; Marinas, J.M.; Romero, A.A.; Calvino, J.J.; Rodríguez-Luque, M.P. Synthesis of acidic Al-MCM-48: Influence of the Si/Al ratio, degree of the surfactant hydroxyl exchange, and post-treatment in NH4F solution. J. Catal. 2005, 230, 327-338. [CrossRef]

20. Rouquerol, J.; Llewellyn, P.; Rouquerol, F. Is the bet equation applicable to microporous adsorbents? Stud. Surf. Sci. Catal. 2007, 2991, 49-56. [CrossRef]

21. Maache, M.; Janin, A.; Lavalley, J.C.; Benazzi, E. FT infrared study of Brønsted acidity of H-mordenites: Heterogeneity and effect of dealumination. Zeolites 1995, 15, 507-516. [CrossRef]

22. Zecchina, A.; Spoto, G.; Ricchiardi, G.; Bordiga, S.; Bonino, F.; Prestipino, C.; Lamberti, C. Zeolite characterization with spectroscopic methods. Stud. Surf. Sci. Catal. 2002, 142, 3-14. [CrossRef]

23. Pazé, C.; Bordiga, S.; Lamberti, C.; Salvalaggio, M.; Zecchina, A.; Bellussi, G. Acidic properties of H- $\beta$ zeolite as probed by bases with proton affinity in the 118-204 kcal mol-1 range: A FTIR investigation. J. Phys. Chem. B 1997, 101, 4740-4751. [CrossRef]

24. Van Bokhoven, J.A.; van der Eerden, A.M.J.; Koningsberger, D.C. Three-coordinate aluminum in zeolites observed with in situ x-ray absorption near-edge spectroscopy at the Al K-edge: Flexibility of aluminum coordinations in zeolites. J. Am. Chem. Soc. 2003, 125, 7435-7442. [CrossRef] [PubMed]

25. Janda, A.; Bell, A.T. Effects of Si/Al ratio on the distribution of framework $\mathrm{Al}$ and on the rates of alkane monomolecular cracking and dehydrogenation in H-MFI. J. Am. Chem. Soc. 2013, 135, 19193-19207. [CrossRef]

26. Kunkeler, P.J.; Zuurdeeg, B.J.; Van Der Waal, J.C.; van Bokhoven, J.A.; Koningsberger, D.C.; Van Bekkum, H. Zeolite Beta the Relationship Between Calcination Procedure, Aluminum Configuration, and Lewis Acidity. J. Catal. 1998, 180, 234-244. [CrossRef]

27. Woolery, G.L.; Kuehl, G.H.; Timken, H.C.; Chester, A.W.; Vartuli, J.C. On the nature of framework Brønsted and Lewis acid sites in ZSM-5. Zeolites 1997, 19, 288-296. [CrossRef]

28. BWouters, H.; Chen, T.H.; Grobet, P.J. Reversible tetrahedral-octahedral framework aluminum transformation in zeolite Y. J. Am. Chem. Soc. 1998, 120, 11419-11425. [CrossRef]

29. Ravi, M.; Sushkevich, V.L.; van Bokhoven, J.A. Lewis Acidity Inherent to the Framework of Zeolite Mordenite. J. Phys. Chem. C 2019, 123, 15139-15144. [CrossRef]

30. Miyaji, A.; Sakamoto, Y.; Iwase, Y.; Yashima, T.; Koide, R.; Motokura, K.; Baba, T. Selective production of ethylene and propylene via monomolecular cracking of pentene over proton-exchanged zeolites: Pentene cracking mechanism determined by spatial volume of zeolite cavity. J. Catal. 2013, 302, 101-114. [CrossRef]

31. Gounder, R.; Iglesia, E. Catalytic consequences of spatial constraints and acid site location for monomolecular alkane activation on zeolites. J. Am. Chem. Soc. 2009, 131, 1958-1971. [CrossRef] [PubMed]

32. Pyra, K.; Tarach, K.A.; Majda, D.; Góra-Marek, K. Desilicated zeolite BEA for the catalytic cracking of LDPE: The interplay between acidic sites' strength and accessibility. Catal. Sci. Technol. 2019, 9, 1794-1801. [CrossRef]

33. Derouane, E.G.; André, J.M.; Lucas, A.A. A simple van der waals model for molecule-curved surface interactions in molecular-sized microporous solids. Chem. Phys. Lett. 1987, 137, 336-340. [CrossRef]

34. Jones, A.J.; Iglesia, E. The Strength of Brønsted Acid Sites in Microporous Aluminosilicates. ACS Catal. 2015, 5, 5741-5755. [CrossRef]

35. Demuth, T.; Hafner, J.; Benco, L.; Toulhoat, H. Structural and Acidic Properties of Mordenite. An ab Initio Density-Functional Study. J. Phys. Chem. B 2000, 104, 4593-4607. [CrossRef]

36. Song, C.; Chu, Y.; Wang, M.; Shi, H.; Zhao, L.; Guo, X.; Yang, W.; Shen, J.; Xue, N.; Peng, L.; et al. Cooperativity of adjacent BrØnsted acid sites in MFI zeolite channel leads to enhanced polarization and cracking of alkanes. J. Catal. 2017, 349, 163-174. [CrossRef]

37. Yang, C.T.; Janda, A.; Bell, A.T.; Lin, L.C. Atomistic Investigations of the Effects of Si/Al Ratio and Al Distribution on the Adsorption Selectivity of n-Alkanes in Brønsted-Acid Zeolites. J. Phys. Chem. C 2018, 122, 9397-9410. [CrossRef]

38. Čapek, L.; Dědeček, J.; Sazama, P.; Wichterlová, B. The decisive role of the distribution of Al in the framework of beta zeolites on the structure and activity of Co ion species in propane-SCR-NO $\mathrm{x}$ in the presence of water vapour. J. Catal. 2010, 272, 44-54. [CrossRef]

39. Xu, B.; Bordiga, S.; Prins, R.; van Bokhoven, J.A. Effect of framework Si/Al ratio and extra-framework aluminum on the catalytic activity of Y zeolite. Appl. Catal. A Gen. 2007, 333, 245-253. [CrossRef] 
40. Arsenova, N.; Bludau, H.; Haag, W.O.; Karge, H.G. In situ IR spectroscopic study of the adsorption behaviour of ethylbenzene and diethylbenzenes related to ethylbenzene disproportionation over HY zeolite. Microporous Mesoporous Mater. 1998, 23, 1-10. [CrossRef]

41. Castaño, P.; Elordi, G.; Olazar, M.; Aguayo, A.T.; Pawelec, B.; Bilbao, J. Insights into the coke deposited on HZSM-5, H $\beta$ and HY zeolites during the cracking of polyethylene. Appl. Catal. B Environ. 2011, 104, 91-100. [CrossRef]

42. Barrett, E.P.; Joyner, L.G.; Halenda, P.P. The Determination of Pore Volume and Area Distributions in Porous Substances. I. Computations from Nitrogen Isotherms. J. Am. Chem. Soc. 1951, 73, 373-380. [CrossRef]

43. Sadowska, K.; Góra-Marek, K.; Datka, J. Hierarchic zeolites studied by IR spectroscopy: Acid properties of zeolite ZSM-5 desilicated with $\mathrm{NaOH}$ and $\mathrm{NaOH}$ /tetrabutylamine hydroxide. Vib. Spectrosc. 2012, 63, 418-425. [CrossRef]

44. Góra-Marek, K.; Derewiński, M.; Sarv, P.; Datka, J. IR and NMR studies of mesoporous alumina and related aluminosilicates. Catal. Today 2005, 101, 131-138. [CrossRef]

Sample Availability: Not available.

(C) 2020 by the authors. Licensee MDPI, Basel, Switzerland. This article is an open access article distributed under the terms and conditions of the Creative Commons Attribution (CC BY) license (http://creativecommons.org/licenses/by/4.0/). 